\title{
Multiphase Flow Behavior of Layered Methane Hydrate Reservoir Induced by Gas Production
}

\author{
Yilong Yuan, Tianfu Xu, Xin Xin, and Yingli Xia \\ Key Laboratory of Groundwater Resources and Environment, Ministry of Education, Jilin University, Changchun 130021, China \\ Correspondence should be addressed to Tianfu Xu; tianfu_xu@jlu.edu.cn
}

Received 12 July 2017; Accepted 12 October 2017; Published 29 November 2017

Academic Editor: Dan Lu

Copyright (C) 2017 Yilong Yuan et al. This is an open access article distributed under the Creative Commons Attribution License, which permits unrestricted use, distribution, and reproduction in any medium, provided the original work is properly cited.

\begin{abstract}
Gas hydrates are expected to be a potential energy resource with extensive distribution in the permafrost and in deep ocean sediments. The marine gas hydrate drilling explorations at the Eastern Nankai Trough of Japan revealed the variable distribution of hydrate deposits. Gas hydrate reservoirs are composed of alternating beds of sand and clay, with various conditions of permeability, porosity, and hydrate saturation. This study looks into the multiphase flow behaviors of layered methane hydrate reservoirs induced by gas production. Firstly, a history matching model by incorporating the available geological data at the test site of the Eastern Nankai Trough, which considers the layered heterogeneous structure of hydrate saturation, permeability, and porosity simultaneously, was constructed to investigate the production characteristics from layered hydrate reservoirs. Based on the validated model, the effects of the placement of production interval on production performance were investigated. The modeling results indicate that the dissociation zone is strongly affected by the vertical reservoir's heterogeneous structure and shows a unique dissociation front. The beneficial production interval scheme should consider the reservoir conditions with high permeability and high hydrate saturation. Consequently, the identification of the favorable hydrate deposits is significantly important to realize commercial production in the future.
\end{abstract}

\section{Introduction}

Natural gas hydrate $(\mathrm{NGH})$ is solid crystalline compound in which gas molecules are encaged inside the lattices of ice crystals under proper thermodynamic conditions $[1,2]$. In nature, the dominant gas in $\mathrm{NGH}$ is methane, which forms at low temperature and high pressure with extensive distribution in the permafrost and in deep marine sediments $[1,3,4]$. The evaluation results show that the global quantity of hydrocarbon gas hydrates varies widely between $10^{15}$ and $10^{18} \mathrm{ST} \mathrm{m}^{3}$ (ST represents the standard conditions) [2, 5]. As an unconventional energy resource, the exploitation of NGH has attracted significant interest around the world [6].

Gas production from hydrate-bearing sediments (HBS) could be realized by dissociating solid-state hydrate into fluid phases (e.g., gas and water). Multiple methods have been proposed and employed to decompose hydrate for gas recovery from the HBS, such as depressurization, thermal stimulation, gas exchange, and the use of hydration inhibitors (such as salts and alcohols) [2,5-8]. The above methods have been compared in terms of energy efficiency, economic and technological feasibility, and environmental performance [1, $4,9,10]$. Past laboratory and field tests and numerical studies showed that depressurization is the most potential method for gas recovery from HBS, while the other methods may be suitable for enhancing recovery or reservoir stimulation $[4,11,12]$. The obvious advantages of depressurization method include its simplicity and technical effectiveness $[2,13]$.

In order to seek the most technically and economically feasible method for production from the hydrate deposits, numerical simulation was considered the best way to achieve this objective. Moridis et al. [1,2] investigated the gas production potential from Class 1 and Class 2 hydrate deposits through depressurization. They found that large volumes of gas can be produced at high rates for long times from Class 1 hydrate deposits by using conventional technology. Li et al. [14] investigated the effects of confined formation permeability on the gas production potential from marine hydrate deposit. They indicated that the hydrate deposit with impermeable boundaries was expected to be the potential gas 
production target. Huang et al. [15] investigated the effects of geologic conditions on the hydrate dissociation and gas production through depressurization. Their results indicated that permeability, porosity, and initial hydrate saturation have significant effects on gas production performance. Hou et al. [16] numerically investigated the production characteristics of gas hydrate deposits by cyclic hot water stimulation with a separated-zone horizontal well. They indicated that the method combining depressurization and thermal stimulation can improve the hydrate production effectively. Based on the latest geological data in the Eastern Nankai Trough, the longterm production behavior was investigated by Sun et al. [17] and Konno et al. [4]. Both of their results indicated that the gas production rate is expected to increase with time and the simulated water recovery rate cannot match field measured data. In addition, the geomechanical behaviors (such as seafloor subsidence and sand production) of the marine HBS induced by gas production have been widely studied $[3,7,18-$ 21]. The geomechanical analysis indicated that the spatial evolution of the temperature, pressure, hydrate saturation, and gas saturation is the most relevant to the geomechanical behavior of HBS.

The above research has properly promoted the development of gas production from hydrate deposits; however, most of previous numerical studies assume homogeneous reservoirs with a single layer due to absence of substantial geological structure and field test data, resulting in inaccurate estimation of gas productivity and reservoir characteristics. In fact, the marine gas hydrate drilling explorations at the Eastern Nankai Trough of Japan and in Shenhu area of the South China Sea revealed the variable distribution of hydrate deposits. Gas hydrate reservoirs are composed of alternating beds of sand and clay in sediments with various conditions of permeability, porosity, and hydrate saturation [22, 25]. Consequently, the development of suitable geological model is critical to identify the dissociation layers and dissociation front induced by depressurization, which are key factors to ensure the success of the next long-term offshore production test $[3,4,19,22]$. Additionally, the sensitivity analyses of gas production potential in previous studies were concentrated on production pressure, reservoir permeability, porosity, hydrate saturation, thickness, and initial temperature and pressure of HBS [11, 12, 14, 15, 26], whereas comprehensive studies related to the effects of well production interval on gas recovery have been reported sparsely, which are important for the optimization of gas production and reducing the water production rate.

In this paper, we extensively used the borehole geophysical logging, seismic interpretation, and core analyses at the production test site of the Eastern Nankai Trough reported previously by Japanese investigators. A more realistic reservoir model, which considers the layered heterogeneous structure of hydrate saturation, permeability, and porosity, was constructed to improve the simulation accuracy. The model we developed was validated by comparing the simulation results with actual test data of well production. The reservoir's responses and multiphase movement behaviors of water and gas during the production test were analyzed and discussed in detail. Furthermore, we use the validated model to investigate

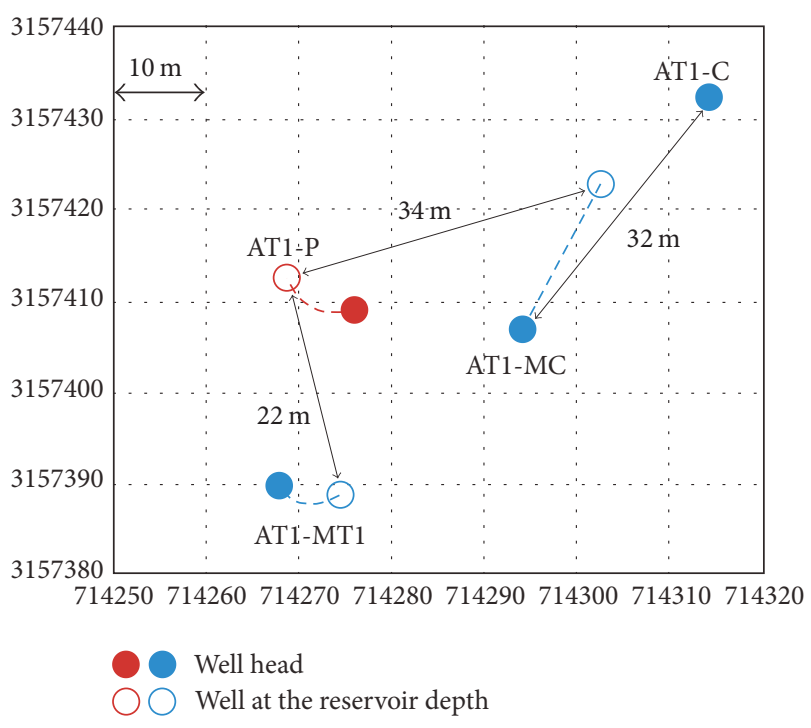

FIGURE 1: Horizontal section showing the locations of production, monitoring, and sampling wells at the AT1 site [4].

the effects of the placement of production interval on the production performance. Overall, this work may provide a useful method and some feasible suggestions for the subsequent test and future commercial production under similar reservoir conditions.

\section{Overview of the Test Site of Nankai Trough}

2.1. Site Conditions. The Eastern Nankai Trough is the most potential resource-rich area of gas hydrates in Japan [22, 27]. In this area, the total amount of $\mathrm{CH}_{4}$ gas contained in HBS was estimated at an average value of $1.1 \times 10^{12} \mathrm{~m}^{3}$, most of which was reserved in the 16 methane hydrate concentrated zones (MHCZs) [4, 22, 28]. MHCZ was characterized as sand-dominant methane hydrate with high saturation [4]. The AT1 site within the $\beta$-MHCZ, located in the north slope of Daini Atsumi Knoll area, is the 2013 production test site $[22,29]$. The area of $\beta-\mathrm{MHCZ}$ is about $12 \mathrm{~km}^{2}$ with the water depth ranging from 857 to $1405 \mathrm{~m}[22,28]$. The thickness of MHCZ is dozens of meters, which is composed of turbidite channel-type sediments [22].

2.2. Well Distribution and Formation Evaluations. In 2012, the production well (AT1-P), two monitoring wells (AT1-MC and AT1-MT1), and sampling well (AT1-C) were drilled at the AT1 site $[22,29]$. The well locations and their trajectories projected in the horizontal section are shown in Figure 1. The extensive logging programs were conducted at wells AT1-P, MC, and MT1 in 2012 to evaluate reservoir properties and to determine the production interval $[22,28]$. In addition, pressure coring was conducted at well AT1-C to collect essential geological and geochemical data and to correct in situ formation parameters $[22,30]$.

Figure 2 shows the detailed resistivity images at three wells (AT1-P, MC, and MT1) at the AT1 site. As shown in Figure 2, the target MHCZ (Unit IV) has a gross thickness of 




(a) AT1-MT1

(b) AT1-P

(c) AT1-MC

FIgure 2: Resistivity images of three wells AT1-P, MT1, and MC at the AT1 site. The red color indicates the highly methane hydrate saturation sandy layers. The resistivity image logging indicated the stratum at the AT1 site with a dip angle approximately $20^{\circ}$; thus, well AT1-P was located slightly down-dip from wells AT1-MC and MT1 $[22,23]$.

$61 \mathrm{~m}$ [22]. On the basis of lithological structure, the MHCZ is divided into three major subzones [22, 23]. Unit IV-1 is composed of thin alternating beds of sand and mud in the upper part and sand layers with thicknesses of $30-70 \mathrm{~cm}$. Unit IV-2 also contains alternations of sand and silt in the middle part but with lower hydrate saturation. Unit IV-3 is composed of sand-dominant layers in the lower part with high hydrate saturation, and the thicknesses of sand layers range from dozens of centimeters to $2 \mathrm{~m}$.
2.3. Quantification of Properties and Physical Conditions. Figure 3 shows the depth profiles of hydrate saturation, porosity, absolute permeability, and resistivity image. Hydrate saturation (Figure 3(a)) was estimated by using the Archie equation [31]. The validity of the derived saturation was confirmed by the pressure core data [22]. The porosities (Figure 3(b)) mainly ranging from 0.4 to 0.5 were determined from the density log. These are validated by the core derived porosities, which were measured under in situ confining 


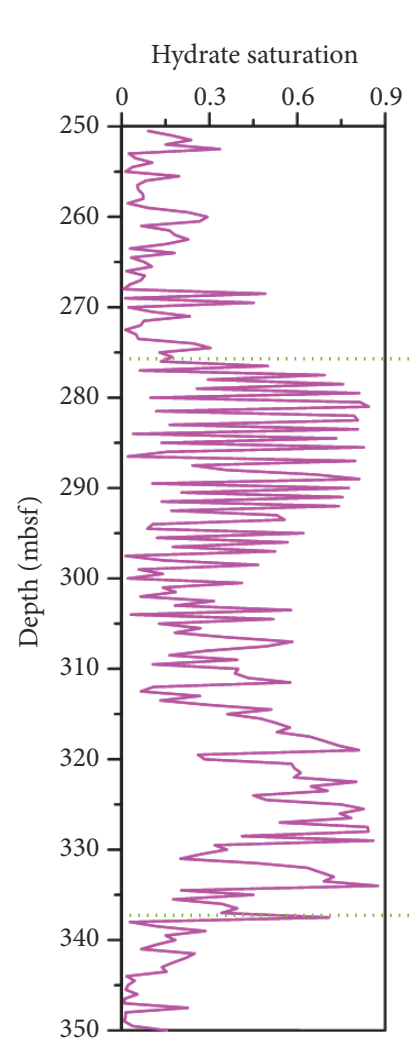

(a)

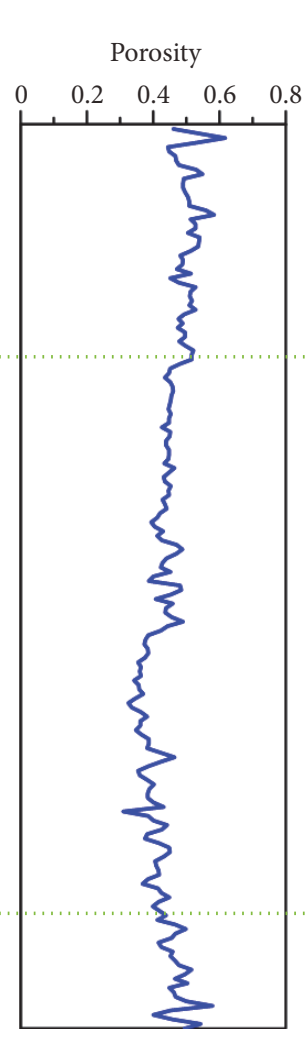

(b)

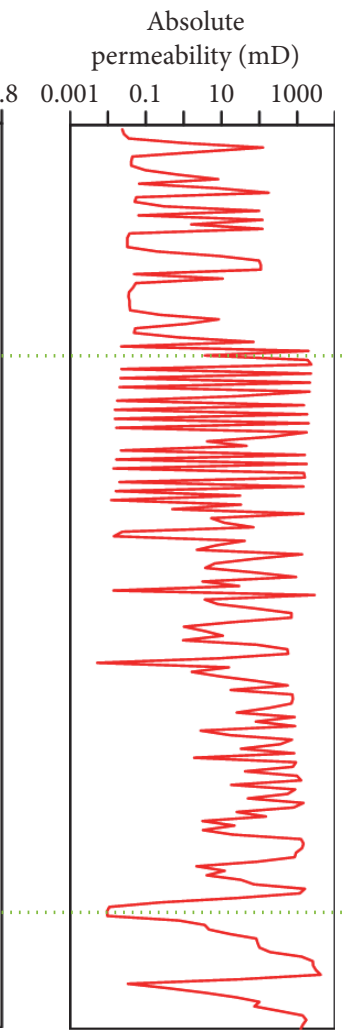

(c)
Resistivity
image

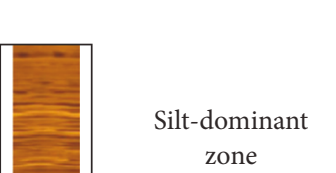

(seal formation)

FIGURE 3: Depth profiles of hydrate saturation, porosity, and absolute permeability based on the well logging and core data with resistivity image $[4,22,24]$. Green dotted lines show the position of the top and bottom of the MHCZ.

pressure $[22,23]$. The absolute permeability (intrinsic permeability, Figure 3(c)) was estimated by using the KozenyCarman model and calibrated with the core data collected from hydrate reservoirs at the Eastern Nankai Trough [23, 24].

\section{Simulation Model}

3.1. The Numerical Simulator. In this study, the TOUGH+ HYDRATE simulator was used to investigate the multiphase flow behavior of layered methane hydrate reservoir induced by gas production. This code can model the nonisothermal hydration reaction, multiphase behavior, and flow of fluids and heat under conditions typical in geological media containing gas hydrates $[1,2,5]$. It includes both an equilibrium and a kinetic model of hydrate formation and dissociation [5]. The model accounts for heat and up to four mass components (i.e., $\mathrm{H}_{2} \mathrm{O}, \mathrm{CH} 4$, hydrate, and water-soluble inhibitors such as salts or alcohols). These components are partitioned among four possible phases (i.e., gas, liquid, ice, and hydrate) [2, 5]. The model can describe all possible hydrate dissociation mechanisms, such as depressurization, thermal stimulation, and salting-out effects.

\subsection{Model Geometry, Boundaries, and Spatial Discretization.} The geometry of the axisymmetric cylinder 2D model (RZ2D model) was constructed for the latter history matching simulation as shown in Figure 4 . The model size in $R$-direction is $1000 \mathrm{~m}$ to avoid the boundary effects. The total thickness of the entire model is $100 \mathrm{~m}$ with the thickness of MHCZ being $61 \mathrm{~m}$. The production well with a radius of $0.1 \mathrm{~m}$ is located in the center of the cylinder $[29,32]$. Production interval was $38 \mathrm{~m}$ from the top of the MHCZ for expecting the lower part of MHCZ as sealing layer to prevent water production [22]. Because the radius distance of $1000 \mathrm{~m}$ can effectively avoid the boundary effects in 6-day production test, there is no flow of fluids and heat through the lateral boundary. The top of the silt-dominant zone and the bottom of the water-bearing zone are designed as constant temperature and pressure boundaries [17]. For simulation of the varied depressurization processes (Section 3.5), the time-independent Dirichlet boundary (e.g., constant pressure) conditions are applied to the production well.

Previous studies had indicated that the critical process occurs within a limited range around the production well $[1,2,7]$. Therefore, the grids are refined surrounding the well with the minimum interval of $0.1 \mathrm{~m}$. The grid sizes increase with the distance to the well, which reach a size of $75 \mathrm{~m}$ at the lateral boundary. The discretization for each fine layer at the vertical $Z$-direction is $0.5 \mathrm{~m}$. Figure 5 shows the corresponding grids used in the simulations. The simulation domain was discretized into $200 \times 100$ grids in $R$ - and $Z$ directions.

3.3. Initial Conditions. The initial reservoir pressure was assigned in line with the hydrostatic pressure, which was 




FIGURE 4: The geometry of the simulation domain and the configuration of production well.

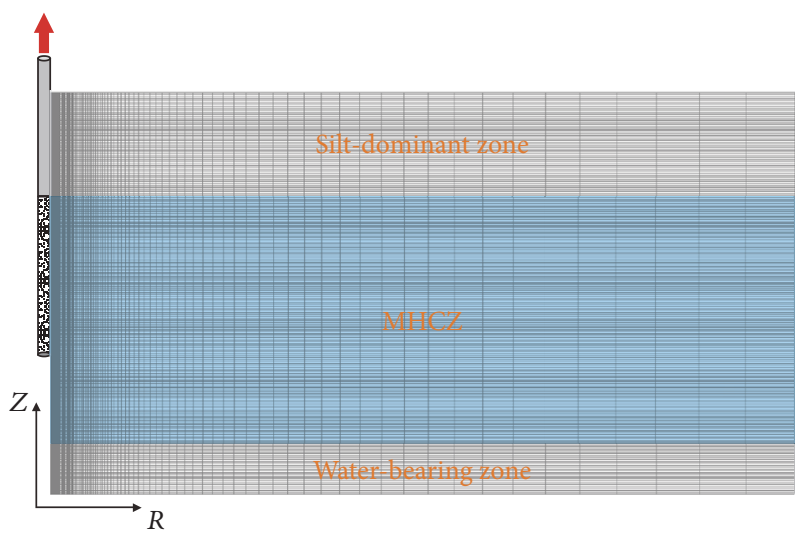

FIGURE 5: The corresponding grids used in the simulations, showing the main subzones at the ATl site of the Eastern Nankai Trough.

computed according to the water depth and a pressureadjusted saline water density $[7,17]$. The initial temperature was specified to be $4^{\circ} \mathrm{C}$ at the seafloor $[11,17,23]$. The temperature profile was assigned to vary linearly as a function of depth with a geothermal gradient of $0.03^{\circ} \mathrm{C} / \mathrm{m}$. The initial hydrate saturation was varied in each fine layer and assumed to be horizontally uniform as shown in Figure 6(a).
3.4. Reservoir Properties and Parameters. Table 1 presents the main modeling parameters and physical properties for the AT1 site sediments at the Eastern Nankai Trough. These were based on the geophysical well logs and core samples analyses from published papers $[4,17,22,23,27,28]$. The permeability and porosity are based on the logging data of AT1-MC and the pressure core data of AT1-C as shown in Figure 3. Hydrate saturations obtained from geophysical logging data were validated by those evaluated by pressure core analysis. The wellbore is simulated as a pseudoporous medium with porosity, permeability, capillary pressure, and low irreducible gas saturation of $1.0,1.0 \times 10^{-8} \mathrm{~m}^{2}, 0 \mathrm{MPa}$, and 0.005 , respectively. Earlier studies had shown the validity of this approximation $[33,34]$. The composite thermal conductivity, relative permeability, and capillary pressure models are employed commonly in numerical simulations on gas production from hydrate deposits $[2,7,17,18]$. The corresponding parameters for relative permeability and capillary pressure were determined from the field test data by Moridis and Reagan [34]. The changes of effective permeability and capillary pressure are consistent with the porosity and phase saturation during the simulation.

Well-to-well correlation between three wells (AT1-P, MC, and MT1) shown in Figure 2 exhibited that lateral continuity of these sand layers is fairly good, and the 3D seismic survey suggests the widespread deposits of the turbidite sediments 


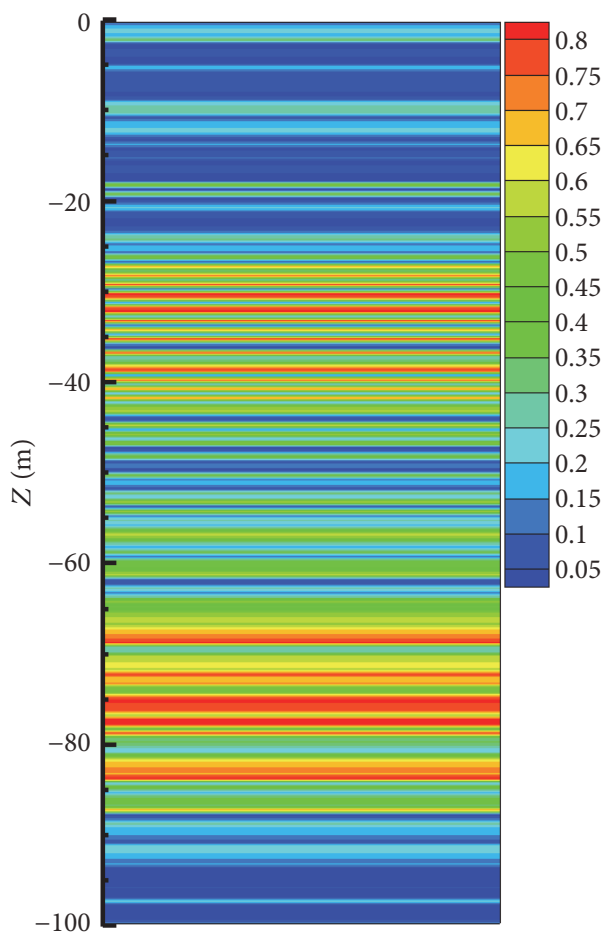

(a) Hydrate saturation

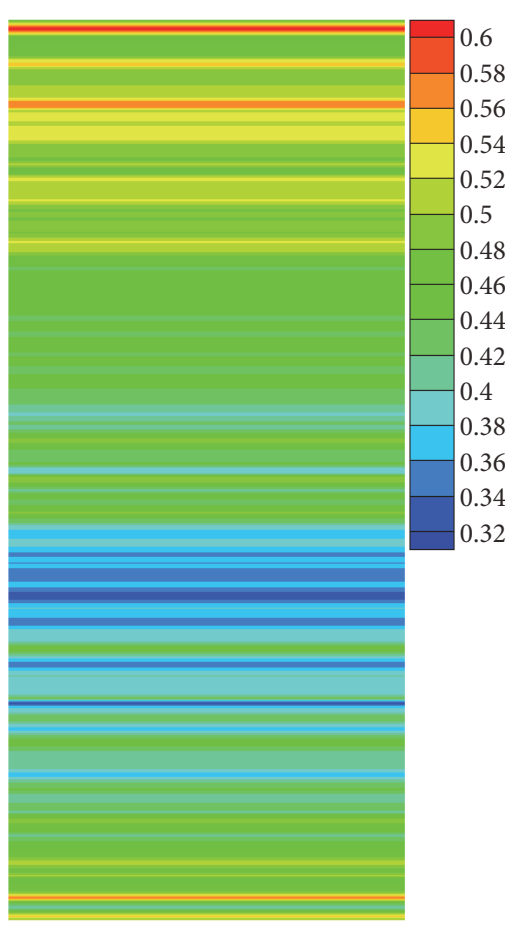

(b) Porosity

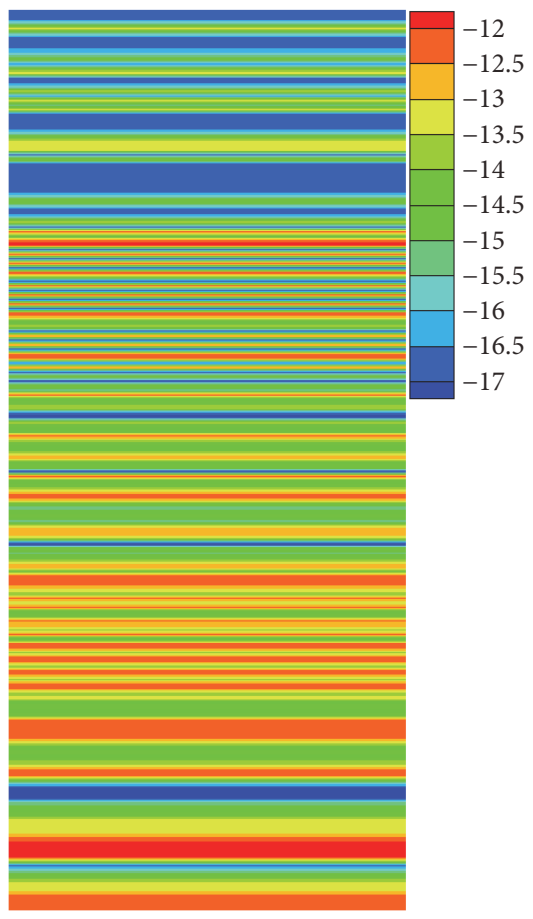

(c) Log permeability

FIGURE 6: Cross-sectional view showing the initial reservoir-model properties: (a) hydrate saturation, (b) porosity, and (c) logarithmic value of absolute permeability.

beyond several kilometers [11, 22, 23]. Consequently, the reservoir properties were assumed to be uniform in each fine layer. Figure 6 shows the cross-sectional views of the initial hydrate saturation, porosity, and absolute permeability in the model.

3.5. Depressurization Scheme. The method used to decompose the solid hydrate was depressurization, which had been successfully applied at the Mallik site, Canada, in 2007 and 2008 [19, 37, 38]. Figure 7 shows the depressurization processes both in field test and in this simulation, which lasted for about 6 days. As shown in Figure 7, the wellbore pressure of production well was decreased from approximately $13 \mathrm{MPa}$ to about $4 \mathrm{MPa}$ during the first day and then remained almost stable for 5 days [29]. In the morning of the 6th day, sudden water rate increase was observed followed by strong sand production to the surface, and then the flow test was terminated [29]. During the stable production period, the volumetric rates of gas and water were approximately 20,000 and $200 \mathrm{~m}^{3} / \mathrm{d}$, and the cumulative volume produced at the well during the period of 6 days was $119,500 \mathrm{~m}^{3}$ and $1,250 \mathrm{~m}^{3}$, respectively $[4,17,29]$.

\section{Simulation Results and Analysis}

4.1. Gas and Water Production Behaviors. By decreasing the wellbore pressure of production well, gas and water flowed into the well due to the pressure gradient of the reservoir. Figure 8 indicates the evolution of the volumetric rate of (a) the model-predicted $\mathrm{CH}_{4}$ production in the well $\left(Q_{\mathrm{Gl}}\right)$, (b) site measured $\mathrm{CH}_{4}$ production in the well $\left(Q_{\mathrm{G} 2}\right)$, and (c) gas released from hydrate dissociation $\left(Q_{R}\right)$. As shown in Figure 8 , the predicted volumetric rates of gas production match well with the measured data by site test. The accumulated volume of gas trapped $\left(V_{\mathrm{G}}\right)$ in 6 days is $122,861 \mathrm{~m}^{3}$; both $Q_{\mathrm{G}}$ and $V_{\mathrm{G}}$ are basically consistent with the field data observed.

Initially $Q_{R}$ and $Q_{G}$ increase quickly because of the significant decrease of borehole pressure during the first day (Figure 7). In the following days, both $Q_{R}$ and $Q_{G}$ begin oscillating around a coarsely invariable value, which clarify the struggle between the impacts of temperature and pressure on hydrate decomposition and gas production [3]. Decreasing pressure causes hydrate decomposition with the increase in $Q_{R}$ and $Q_{G}$. The endothermic nature of hydrate decomposition results in temperature decline and makes further decomposition not easy, resulting in decrease in $Q_{R}$ and $Q_{G}$. Note that the dramatic changes of $Q_{R}$ at about 2.5 days are due to the wellbore pressure disturbance (Figure 7), which indicates that the decomposition of hydrate is extremely sensitive to production pressure. Further consideration of the difference between $Q_{R}$ and $Q_{G}$ suggests that the released gas cannot be trapped completely and most of which still remained in the hydrate reservoirs. Consequently, the optimization of well configuration and production strategies are needed to improve the gas recovery efficiency.

Figure 9 shows the evolution of volumetric rates of simulated $\left(Q_{\mathrm{W} 1}\right)$ and measured $\left(Q_{\mathrm{W} 2}\right)$ water production in the well. The predicted water production rate is about $300 \mathrm{~m}^{3} / \mathrm{d}$, which is slightly higher than that of site measured rate of $200 \mathrm{~m}^{3} / \mathrm{d}$. This may be because (1) the geomechanical 
TABLE 1: Hydrate deposit properties at the AT1 site.

\begin{tabular}{|c|c|}
\hline Parameter & Value \\
\hline MHCZ thickness, $H$ & $61 \mathrm{~m}$ \\
\hline Gas composition & $100 \% \mathrm{CH} 4$ \\
\hline Water salinity, $X_{i}$ & $3.50 \%$ \\
\hline $\begin{array}{l}\text { Pressure at the base of } \\
\text { the MHCZ, } P_{b}\end{array}$ & 14.7 MPa \\
\hline $\begin{array}{l}\text { Temperature at the } \\
\text { base of the MHCZ, } T_{b}\end{array}$ & $14.3^{\circ} \mathrm{C}$ \\
\hline $\begin{array}{l}\text { Critical mobile } \\
\text { porosity, } \phi_{\text {cri }}\end{array}$ & 0.05 \\
\hline Rock grain density, $\rho_{R}$ & $2650 \mathrm{~kg} / \mathrm{m}^{3}$ \\
\hline $\begin{array}{l}\text { Wet thermal } \\
\text { conductivity, } \lambda_{W}\end{array}$ & $3.1 \mathrm{~W} / \mathrm{m} / \mathrm{K}$ \\
\hline $\begin{array}{l}\text { Dry thermal } \\
\text { conductivity, } \lambda_{D}\end{array}$ & $1.0 \mathrm{~W} / \mathrm{m} / \mathrm{K}$ \\
\hline Pore compressibility, $\alpha_{P}$ & $1.0 \times 10^{-8} \mathrm{~Pa}^{-1}$ \\
\hline $\begin{array}{l}\text { Composite thermal } \\
\text { conductivity model } \\
\text { [35] }\end{array}$ & $\lambda=\lambda_{D}+\left(S_{A}^{1 / 2}+S_{h}^{1 / 2}\right)\left(\lambda_{W}-\lambda_{D}\right)+\phi S_{I} \lambda_{I}$ \\
\hline $\begin{array}{l}\text { Capillary pressure } \\
\text { model [36] }\end{array}$ & $\begin{array}{c}P_{\text {cap }}=-P_{0}\left(\left[S_{A}^{*}\right]^{-1 / m}-1\right)^{1 / m} \\
S_{A}^{*}=\frac{\left(S_{A}-S_{i r A}\right)}{\left(S_{m x A}-S_{i r A}\right)}\end{array}$ \\
\hline$S_{m x A}$ & 1.0 \\
\hline$m$ & 0.45 \\
\hline$P_{0}[17]$ & $1.0 \times 10^{5} \mathrm{~Pa}$ \\
\hline $\begin{array}{l}\text { Relative permeability } \\
\text { model [7] }\end{array}$ & $\begin{array}{c}k_{r A}=\left(S_{A}^{*}\right)^{n_{A}} \\
k_{r G}=\left(S_{G}^{*}\right)^{n_{G}} \\
S_{G}^{*}=\frac{\left(S_{G}-S_{i r G}\right)}{\left(1-S_{i r G}\right)}\end{array}$ \\
\hline$n_{A}[34]$ & 3.572 \\
\hline$n_{G}$ & 3.572 \\
\hline$S_{i r A}$ & 0.20 \\
\hline$S_{i r G}$ & 0.02 \\
\hline
\end{tabular}

response during depressurization production from the HBS is not considered in our model, which means that the reservoir compression has immediate effects on decreases in formation porosity and intrinsic permeability and then on the fluidflow behavior [3,19]; (2) the well completion methods used at the field relate to prevent water from reservoir flow into the production well as explained by Yamamoto et al. [29] and Sun et al. [17]; (3) the exposure of clay minerals of marine deposit to fresh water (released from hydrate dissociation) can induce swelling and structural weakening $[7,18]$; $(4)$ the complex and inevitable horizontal heterogeneity in each fine layer is also neglected in our model. In fact, these factors mentioned above have little effect on gas production, because gas viscosity is much smaller than that of water and gas slippage effects in the low-permeability deposits exist [5]. As a consequence, the predicted gas production rates are basically consistent with the site measured data, while the predicted water production rates are higher than that in the field.

The stable depressurization and gas production at the AT1 site of the Eastern Nankai Trough proved that hydrate

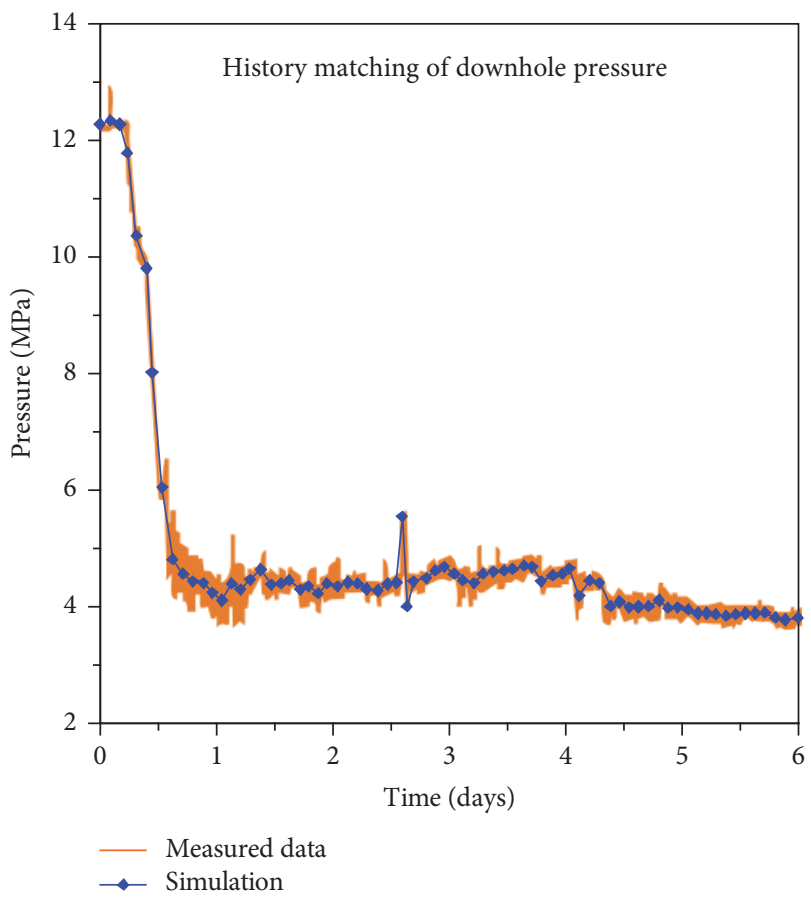

Figure 7: Depressurization processes of the production test at the AT1 site in the Eastern Nankai Trough.

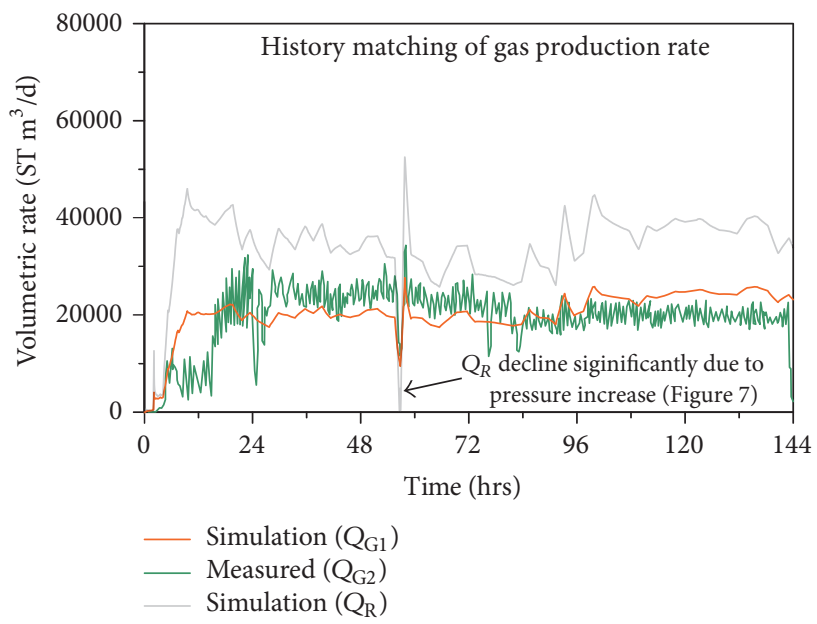

FIGURE 8: Gas release $\left(Q_{R}\right)$ and production $\left(Q_{G}\right)$ rates during the 6-day production test at the AT1 site.

decomposition by depressurization is applicable even in the marine sediments. Over and above the absolute criteria of $Q_{R}$ and $Q_{\mathrm{G}}$ to evaluate the production potential, the cumulative water/gas ratio $R_{\text {CWG }}$ provides a relative criterion to evaluate the overall operation performance of the system, which is defined as [7]

$$
R_{\mathrm{CWG}}=\frac{\int Q_{\mathrm{W}} \mathrm{d} t}{\int \mathrm{Q}_{\mathrm{G}} \mathrm{d} t} .
$$

Figure 10 indicates the evolution of the simulated $R_{\text {CWG }}$ during the 6-day production test at the AT1 site, 


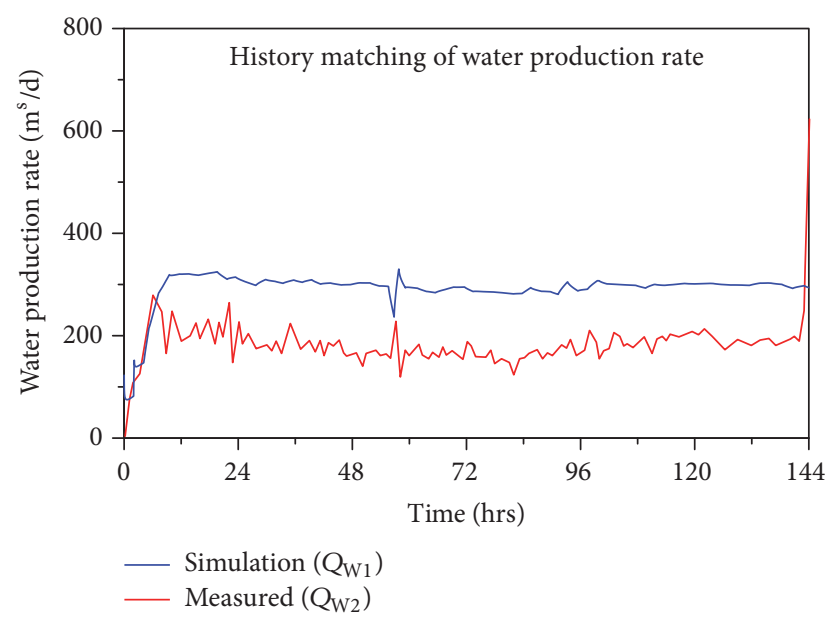

Figure 9: Measured and simulated water production rates $\left(Q_{\mathrm{W}}\right)$ during the 6-day production test at the AT1 site.

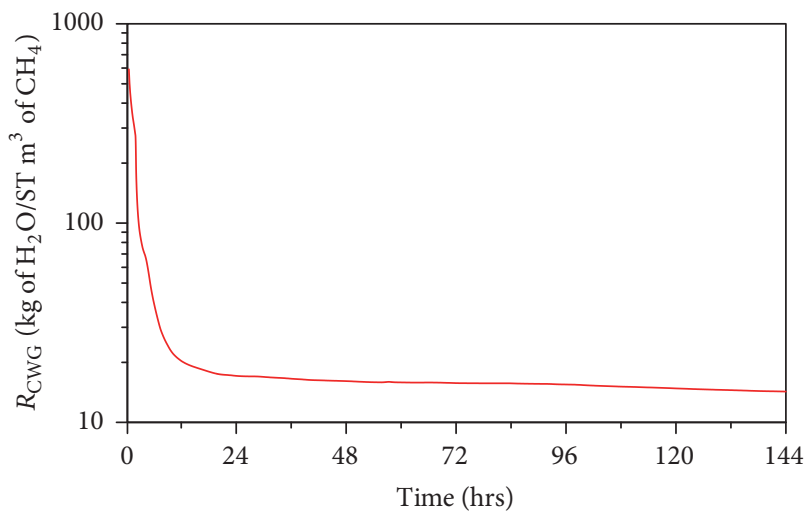

Figure 10: The cumulative water/gas ratio $R_{\text {CWG }}$ during the 6-day production test at the AT1 site.

which declines monotonically with time. This is because of continuous improvement of the gas production. In the early stage, $R_{\mathrm{CWG}}$ drops rapidly because of significant hydrate dissociation in the reservoir and gas recovery at the production well (Figure 8 ). With time advancing, the stability of gas and water output results in slight changes of $R_{\mathrm{CWG}}$. Consequently, $R_{\text {CWG }}$ reaches very low levels of 20 in less than 1 day and is further reduced to $R_{\mathrm{CWG}}=14 \mathrm{~kg}$ of $\mathrm{H}_{2} \mathrm{O} / \mathrm{ST} \mathrm{m}^{3}$ of $\mathrm{CH}_{4}$ at 6 days.

\subsection{History Matching of Temperature Changes at AT1-MT1.} During the offshore production test, two monitoring wells (AT1-MT1 and MC) were designed for monitoring thermal disturbance around the production well (AT1-P). Figure 11 shows the monitored and simulated temperature changes at the location of the monitoring well AT1-MT1 on day 5. Measured data indicate that temperature decreases broadly occurred in the upper MHCZ and slightly in the lower MHCZ, which are mainly controlled by the location of production interval (Figure 4). The maximum changes of temperature reach the value of $0.6^{\circ} \mathrm{C}[4,39]$; such a temperature decrease cannot be explained purely from the heat

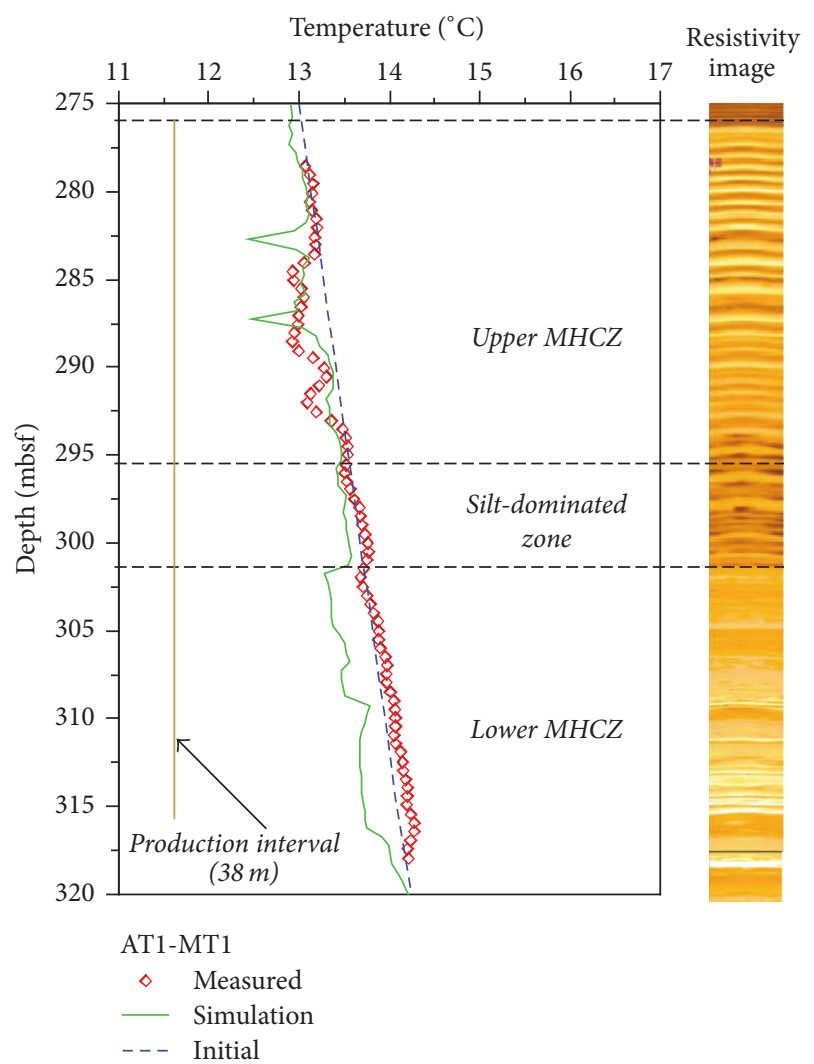

FIGURE 11: Measured and simulated temperature changes at the location of monitoring well AT1-MT1 on day 5 with resistivity image. Initial temperature profile is also shown in the figure with dashed blue line. The offset of the monitoring well AT1-MT1 from the production well AT1-P is $22 \mathrm{~m}$ at the reservoir depth as shown in Figure 1 .

conduction (significantly long time is needed) according to Kanno et al. [39]. Therefore, the hydrate dissociations occurred at the location of the well AT1-MT1. The modelpredicted temperature changes at well AT1-MT1 match well with the measured data, especially in the silt-dominated zone that showed slight change of temperature for both measured and simulated results.

4.3. Evolution of Physical Properties. For the multiphase flow system induced by depressurization, the dynamic evolutions of reservoir properties including pressure, temperature, hydrate, and gas saturation should be analyzed in detail. This is crucial knowledge for the later long-term production test of marine gas hydrate. In addition, the evolution of these variables is important to determine the geomechanical behaviors (such as sand production) in the Eastern Nankai Trough, which are key factors to ensure the success of the offshore production test.

4.3.1. Spatial Distribution of Pressure. Figure 12 indicates the evolution of pressure in the hydrate reservoir due to depressurization. White dashed lines show the position of the top and bottom of the MHCZ. Because the fine sand layers with high hydrate saturation and permeability 




FIGURE 12: Evolution of spatial distribution of pressures in the hydrate reservoir at the AT1 site.
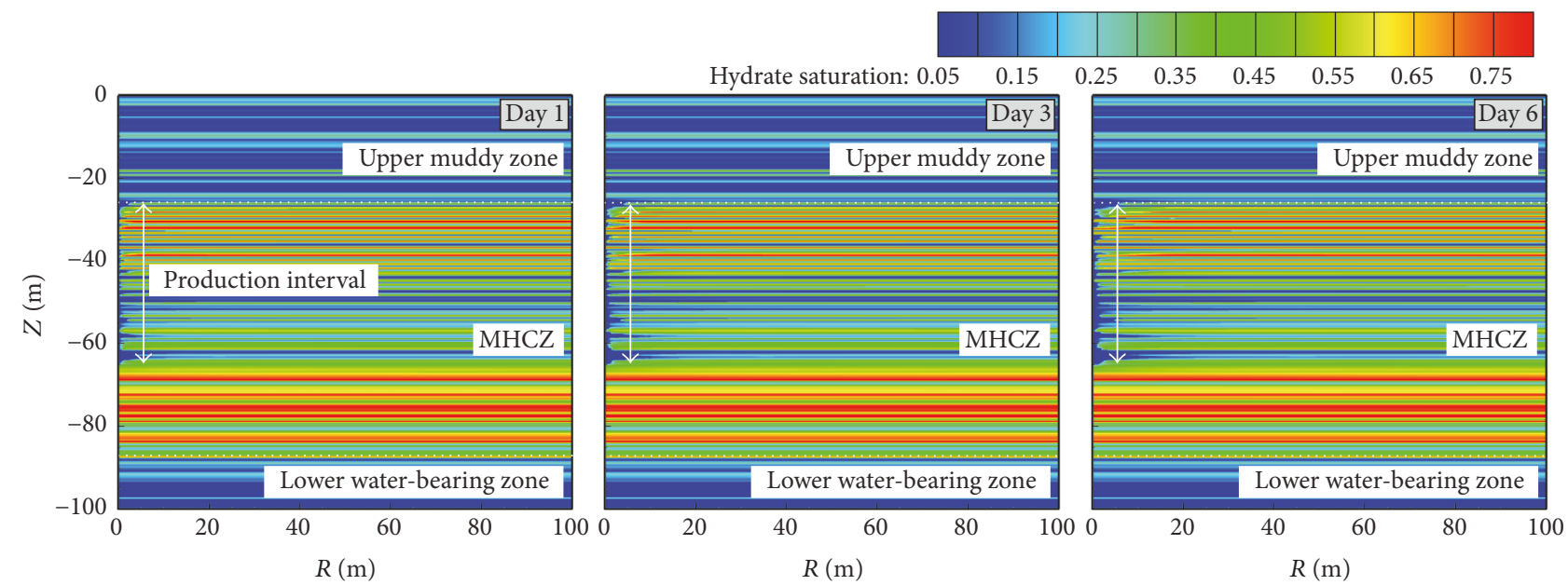

FIGURE 13: Evolution of spatial distribution of hydrate saturation in the hydrate reservoir at the AT1 site.

are hydraulically confined by silt/mud layers in MHCZ, depressurization is anticipated to be quickly and effectively propagated in the horizontal direction. In the early stage, the low pressure at the production well and the low effective permeability of MHCZ create a high pressure gradient near the production well. This pressure gradient extends laterally along the radial direction and tends to be stable with the gradual pressure diffusion. As hydrate dissociation results in increase of effective permeability, depressurization occurs more rapidly in the dissociated region. Due to the transmitted nature of pressure (e.g., even when fluid flow is restricted), the disturbance region of pressure is obviously larger than that of other reservoir properties (Figures 13-15). The effect of depressurization in the hydrate reservoir propagates laterally over $150 \mathrm{~m}$ during the 6 -day production test.
4.3.2. Spatial Distribution of Hydrate Saturation. The decrease in pore-water pressure (Figure 12) drives the hydrate to dissociate around the well in the production interval (Figure 13). As mentioned above, hydrate dissociation increases the effective permeability of the deposits. This process and the anisotropic permeability conditions accelerate the pressure decrease in the radial direction. Consequently, the hydrate dissociates more in the radial direction than in the vertical direction (Figure 13). Overall, the dissociation zone is strongly affected by the vertical reservoir heterogeneity and shows a unique dissociation front. The spatial distribution of hydrate saturation indicates that hydrate has completely dissociated within a few meters around the well. Comparison with the initial hydrate distribution indicates the extent of dissociation zone within $35 \mathrm{~m}$ during the 6 -day production test. 


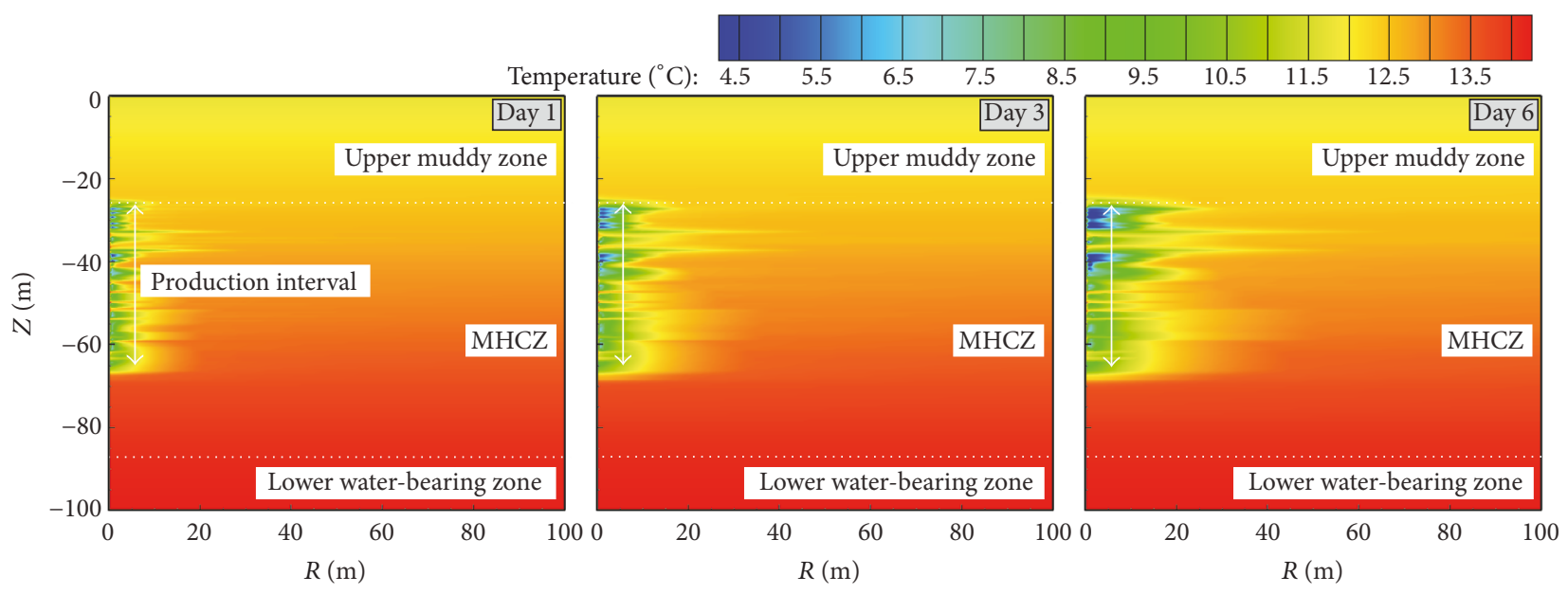

FIGURE 14: Evolution of spatial distribution of temperature in the hydrate reservoir at the AT1 site.

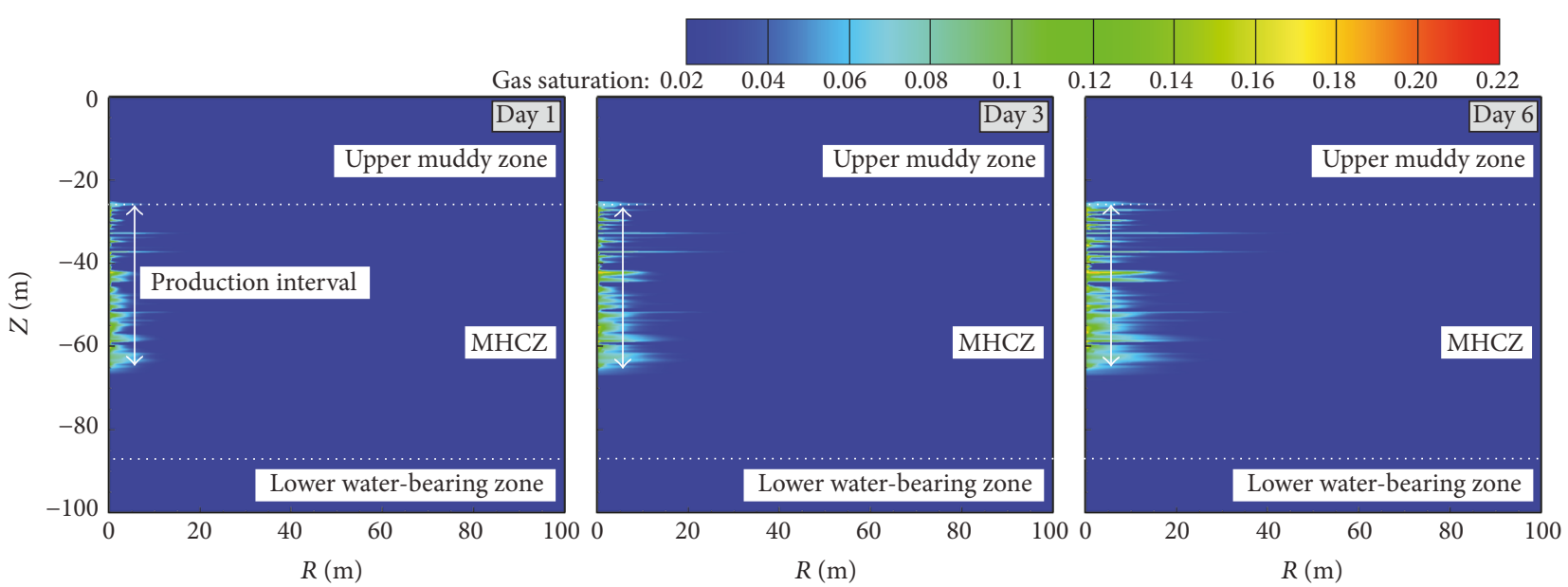

FIGURE 15: Evolution of spatial distribution of gas saturation in the hydrate reservoir at the AT1 site.

4.3.3. Spatial Distribution of Temperature. The temperature reduction is strongly related to the hydrate dissociation because of the endothermic function of hydrate dissociation (Figure 14). The spatial distribution of low temperature shows vertical heterogeneity as well. This is because of the drastic dissociation in the fine sand layers (with high hydrate saturation and high permeability) resulting in significant temperature decreases, whereas the silt-dominant zones with low hydrate saturation undergo slight temperature decreases. Generally, the evolution of low temperature region can reveal the dissociation performance directly.

4.3.4. Spatial Distribution of Gas Saturation. Figure 15 indicates the spatial distribution of gas saturation in the reservoir due to depressurization. The evolution of spatial distribution of free gas is very important for us to understand the gas production behaviors and to evaluate the formation of "secondary hydrate" [17]. As the depressurization begins, there gradually forms a gas bank around and below the production well with the maximum gas saturation of 0.22 .
With time advancing, the region of gas zone gradually enlarges (Figure 15). Gas accumulation is observed around and below the production interval because of continuing hydrate dissociation. However, results of Rutqvist and Moridis [7] indicate that gas accumulation occurred under the bottom of the confined overburden, which results by buoyancy. This phenomenon did not occur in our modeling results, because the hydrate deposits in the case of the Eastern Nankai Trough are composed of alternating beds of sand and clay; thus, the low-permeability sealing formations can effectively prevent gas from migrating upward. This is very important for hydrate exploitation from marine sediments because lack of a confining overburden could result in gas diffusion into the sea floor [7].

\section{Discussion}

The design of production interval is recognized as a significant factor that affects the performance of hydrate exploitation $[12,17]$. The production interval of $38 \mathrm{~m}$ from the 



FIgURE 16: Different designs related to the location of production interval: Case A, from the top of the MHCZ (base case); Case B, at the center of the MHCZ; Case C, from the bottom of the MHCZ.

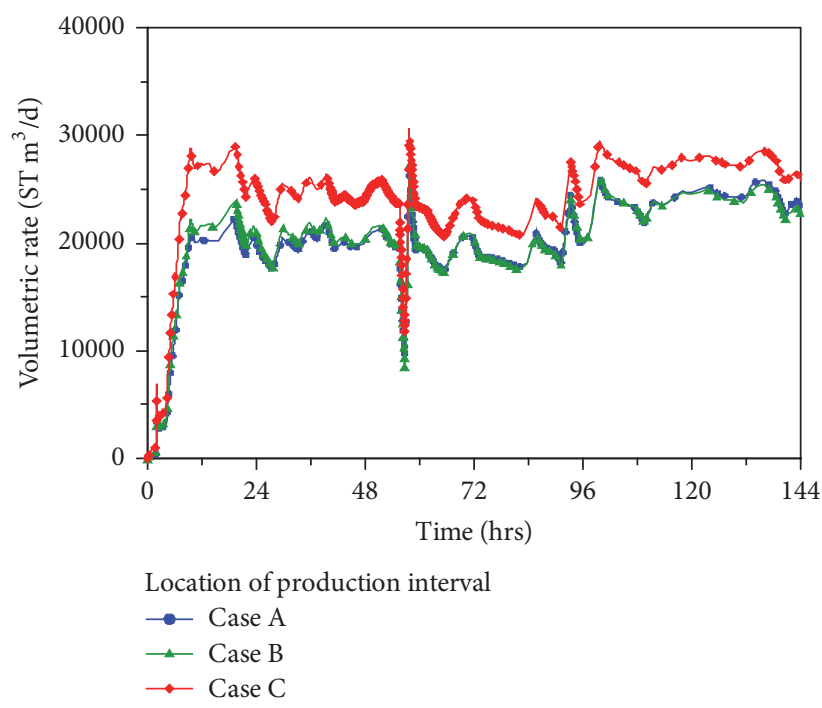

(a)



(b)

FIGURE 17: Evolution of volumetric rates of (a) gas production and (b) water production from hydrate reservoirs under different locations of production interval.

top of the MHCZ (total thickness of $61 \mathrm{~m}$ ) was employed at the AT1 site of the Eastern Nankai Trough (Figure 16, Case A). For effective depressurization, the lower part of the MHCZ (i.e., with high hydrate saturation) was considered as sealing formation to block water production from the underlying water-bearing zones $[22,28]$. Both the site test data and the modeling results indicate the effectiveness of this production interval design by depressurization at marine hydrate deposits. However, the significant gas accumulation is observed at the lower part of the MHCZ and could not sufficiently transport to the production well (Figure 15). This suggests that the gas recovery schemes should be optimized for the subsequent production test.

In this study, three different cases (Figure 16) with different locations of production interval are designed to investigate the effects of placement of production interval on gas production performance. The purpose is to provide some feasible suggestions for the subsequent site test and future large-scale exploitation of gas hydrate. For the convenience of comparison, all of the thermophysical properties of the hydrate reservoirs and production method remain unchanged.

Figure 17 indicates the evolution of model-predicted volumetric rates of gas $\left(Q_{G}\right)$ and water $\left(Q_{W}\right)$ production from hydrate reservoirs under different locations of production interval (Figure 16). As shown in Figure 17(a), the gas production rate in Case $\mathrm{C}$ is significantly higher than that in Case $A$ and Case $B$. The average values of $Q_{G}$ in Case $A$, Case $\mathrm{B}$, and Case $\mathrm{C}$ are about 20477, 20692, and $24307 \mathrm{ST} \mathrm{m}^{3} / \mathrm{d}$, and the accumulated volumes of gas trapped $\left(V_{\mathrm{G}}\right)$ in 6 days are $122,861,124,151$, and $145,843 \mathrm{~m}^{3}$, respectively. On the other side, $Q_{W}$ in Case $B$ and Case $C$ is significantly lower than that in Case $A$. The predicted average values of $Q_{W}$ in Case $A$, Case B, and Case C are approximately 292, 207, and $231 \mathrm{~m}^{3} / \mathrm{d}$, respectively. 


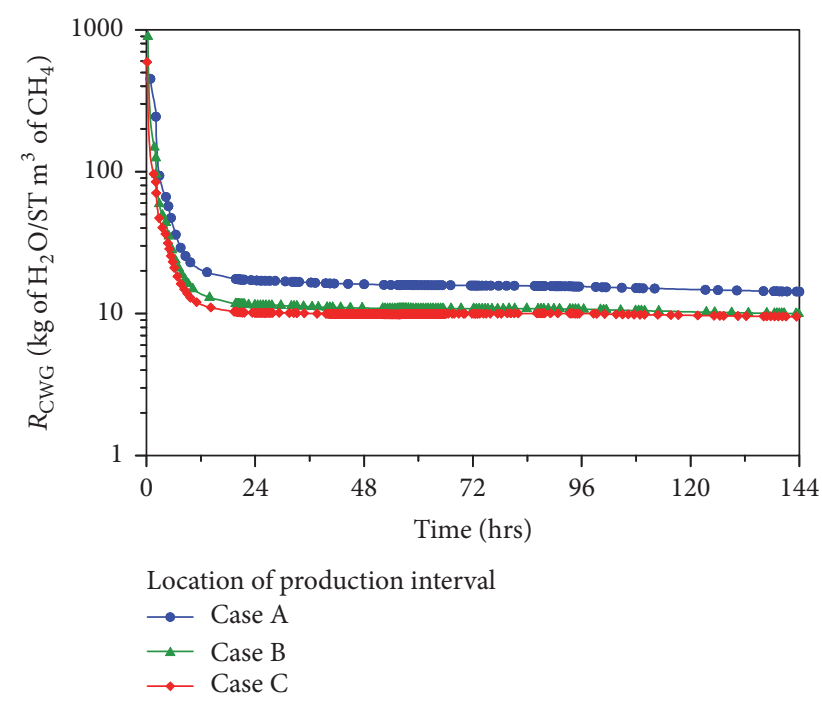

FIgURE 18: The evolution of simulated $R_{\text {CWG }}$ during the 6-day production test under different locations of production interval.

Figure 18 shows the evolution of model-predicted $R_{\mathrm{CWG}}$ during the 6-day production test under different locations of production interval. As mentioned above, $R_{\text {CWG }}$ drops rapidly in the early stage because of the significant hydrate dissociation and gas production (Figure 17(a)). The predicted average values of $R_{\mathrm{CWG}}$ in Case $\mathrm{A}$, Case $\mathrm{B}$, and Case $\mathrm{C}$ are approximately $15.7,10.8$, and $9.9 \mathrm{~kg}$ of $\mathrm{H}_{2} \mathrm{O} / \mathrm{ST} \mathrm{m}^{3}$ of $\mathrm{CH}_{4}$, respectively. Obviously, lower $R_{\mathrm{CWG}}$ indicates higher energy efficiency and economic efficiency of gas hydrate production from marine sediments, because lifting large water volumes to the surface could burden gas production with the cost. Particularly, the disposal of produced low-salinity water (released from hydrate dissociation) may pose environmental damage if released near the sea floor without mixing with sea water at suitable ratios [7].

Both the absolute criteria and relative criteria discussed earlier illustrate the obvious superiority of Case $\mathrm{C}$, in which the production interval is located at the bottom of the MHCZ. This can be explained by the characteristic of flowrelated reservoir properties, as shown in Figure 19. The main reasons include the following: (1) the lower part of MHCZ is composed of thick sand-dominant layers with high initial hydrate saturation and permeability (Figures 3 and 6); the pressure drops rapidly around production interval causing significant hydrate decomposition and gas production; (2) the extent of hydrate dissociation zone is enlarged due to hydrate dissociation which increases the effective permeability and accelerates the pressure reduction in the radial direction; (3) the fluid flow from bottom formations with higher temperature promotes the hydrate dissociation occurring in deeper sediments significantly; (4) the actual reservoir structure with low-permeability silt/mud layers in hydrate deposits can block the water flow through the formation into production well effectively. The simulation results suggest that the favorable production interval scheme should consider the reservoir conditions with high permeability and high hydrate saturation in the subsequent field test and future commercial production. Furthermore, the production behaviors of the hydrate reservoir highly depend on the structure of lithofacies and reservoir properties such as the hydrate saturation and sediments permeability.

\section{Conclusions}

By incorporating the available geological data at the offshore production test site of the Eastern Nankai Trough, a multiphase fluid-flow model was constructed to investigate the gas production performance from the layered hydrate reservoirs by depressurization. The performance affected by the placement of production interval was discussed. Based on the numerical simulations, the following conclusions can be drawn:

(1) The numerical model can match reasonably well with site-observed data of gas recovery. However, a slight deviation occurs between the predicted and measured water production rates. This is mainly due to the geomechanical responses such as reservoir compression, well completion method, clay minerals swelling, and lateral heterogeneity in each fine layer, which are not considered in our model.

(2) Because the fine sand layers with high hydrate saturation are hydraulically confined by silt/mud layers in MHCZ, depressurization is anticipated to be rapidly and effectively propagated, leading to fast hydrate dissociation in the radial direction. As hydrate dissociation results in an increase of effective permeability, this process and the anisotropic permeability conditions accelerate the pressure reduction and hydrate dissociation in the radial direction. Overall, the dissociation zone is strongly affected by the vertical reservoir heterogeneity and shows a unique dissociation front.

(3) The actual reservoir structure with low-permeability silt/mud layers in hydrate reservoirs can block the water flow through the formation into production well. Gas accumulation is observed around and below the production interval, because the low-permeability sealing formations can effectively prevent gas from migrating upward.

(4) The location of production interval is significantly important for the optimization of gas recovery and reduction of water production. The beneficial production interval scheme should consider the reservoir conditions with high permeability and high initial hydrate saturation. Consequently, the identification of favorable hydrate sediments is significantly important to realize commercial production in the future.

\section{Conflicts of Interest}

The authors declare that they have no conflicts of interest. 

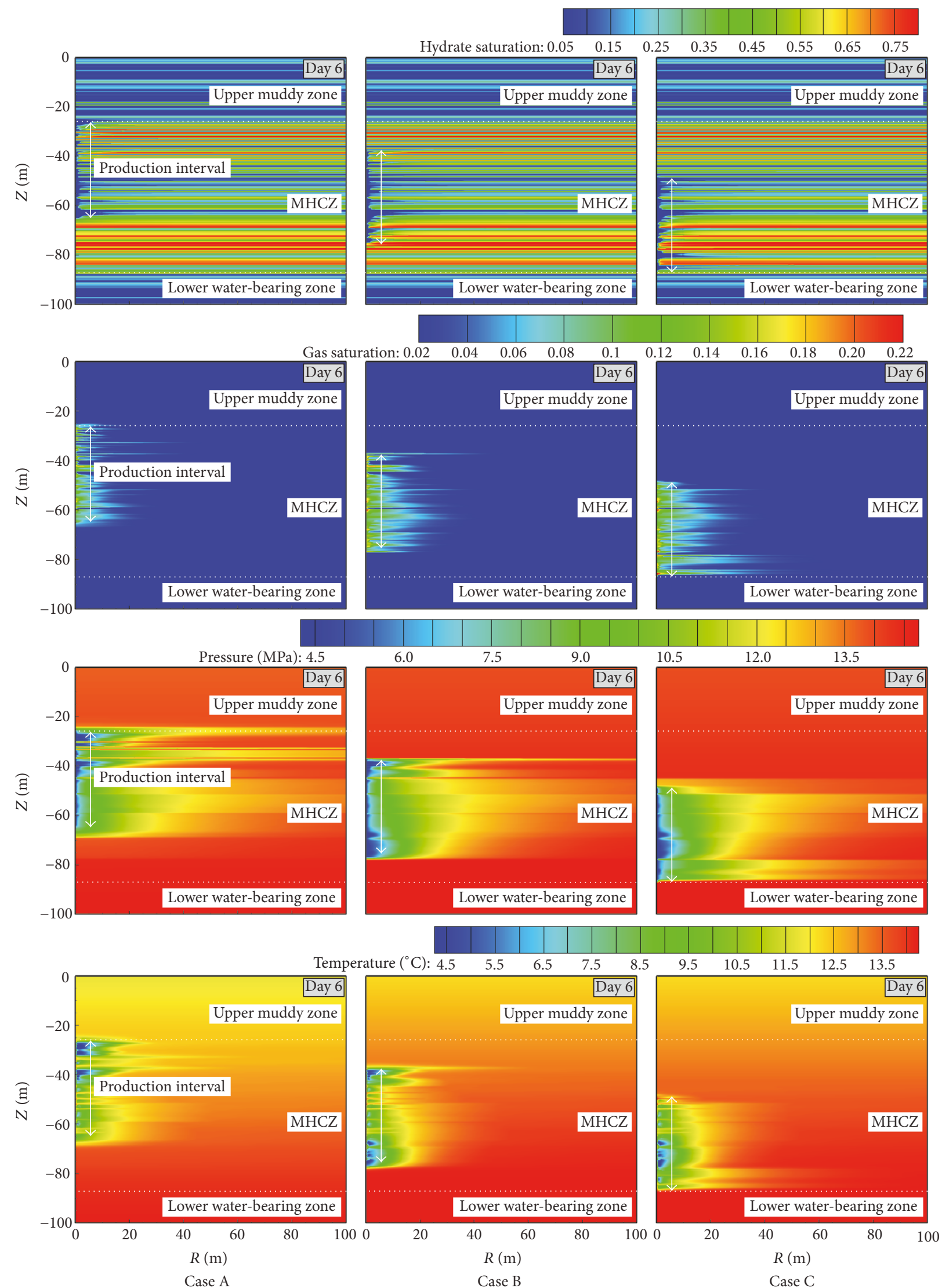

FIGURE 19: The predicted spatial distribution of hydrate and gas saturation, pressure, and temperature at day 6 under different placement of production interval. 


\section{Acknowledgments}

This work was supported by the National Program on Key Research and Development Project (no. 2017YFC0307304) and the Graduate Innovation Fund of Jilin University (no. 2017018).

\section{References}

[1] G. J. Moridis and M. B. Kowalsky, "Depressurization-induced gas production from Class 1 and Class 2hydrate deposits," SPE Reservoir Evaluation and Engineering, vol. 10, no. 5, pp. 458-481, 2005.

[2] G. J. Moridis and M. T. Reagan, "Estimating the upper limit of gas production from Class 2 hydrate accumulations in the permafrost: 2 . Alternative well designs and sensitivity analysis," Journal of Petroleum Science and Engineering, vol. 76, no. 3-4, pp. 124-137, 2011.

[3] J. Rutqvist, G. J. Moridis, T. Grover, and T. Collett, "Geomechanical response of permafrost-associated hydrate deposits to depressurization-induced gas production," Journal of Petroleum Science and Engineering, vol. 67, no. 1-2, pp. 1-12, 2009.

[4] Y. Konno, T. Fujii, A. Sato et al., "Key Findings of the World's First Offshore Methane Hydrate Production Test off the Coast of Japan: Toward Future Commercial Production," Energy \& Fuels, vol. 31, pp. 2607-2616, 2017.

[5] G. Moridis, "User's Manual for the Hydrate v1.5 Option of TOUGH+ v1.5: A Code for the Simulation of System Behavior in Hydrate-Bearing Geologic Media," Tech. Rep. LBNL-6869E, 2014.

[6] G. Jin, T. Xu, X. Xin, M. Wei, and C. Liu, "Numerical evaluation of the methane production from unconfined gas hydratebearing sediment by thermal stimulation and depressurization in Shenhu area, South China Sea," Journal of Natural Gas Science and Engineering, vol. 33, pp. 497-508, 2016.

[7] J. Rutqvist and G. J. Moridis, "Numerical studies on the geomechanical stability of hydrate-bearing sediments," SPE Journal, vol. 14, no. 2, pp. 267-282, 2009.

[8] X. S. Li, C. G. Xu, Y. Zhang, X. K. Ruan, G. Li, and Y. Wang, "Investigation into gas production from natural gas hydrate: A review," Applied Energy, vol. 172, pp. 286-322, 2016.

[9] B. Li, X.-S. Li, G. Li, J.-C. Feng, and Y. Wang, "Depressurization induced gas production from hydrate deposits with low gas saturation in a pilot-scale hydrate simulator," Applied Energy, vol. 129, pp. 274-286, 2014.

[10] B. Li, YP. Liang, Li. XS, and L. Zhou, "A pilot-scale study of gas production from hydrate deposits with two-spot horizontal well system," Applied Energy, vol. 176, pp. 12-21, 2016.

[11] M. Kurihara, A. Sato, H. Ouchi et al., "Prediction of gas productivity from eastern Nankai trough methane-hydrate reservoirs," SPE Reservoir Evaluation and Engineering, vol. 12, no. 3, pp. 477499, 2009.

[12] M. Kurihara, H. Ouchi, A. Sato et al., "Prediction of performances of methane hydrate production tests in the eastern Nankai Trough," in Proceedings of the 7th International Conference on Gas Hydrates, 2011.

[13] R. Swindell and S. Belfroid, "Gas production from oceanic class 2 hydrate accumulations," in Proceedings of Offshore Technology Conference, 2007.

[14] G. Li, X.-S. Li, K. Zhang, B. Li, and Y. Zhang, "Effects of impermeable boundaries on gas production from hydrate accumulations in the shenhu area of the South China sea," Energies, vol. 6, no. 8, pp. 4078-4096, 2013.

[15] L. Huang, Z. Su, N. Wu, and J. Cheng, "Analysis on geologic conditions affecting the performance of gas production from hydrate deposits," Marine and Petroleum Geology, vol. 77, pp. $19-29,2016$.

[16] J. Hou, Z. Xia, S. Li, K. Zhou, and N. Lu, "Operation parameter optimization of a gas hydrate reservoir developed by cyclic hot water stimulation with a separated-zone horizontal well based on particle swarm algorithm," Energy, vol. 96, pp. 581-591, 2016.

[17] J. Sun, F. Ning, L. Zhang et al., "Numerical simulation on gas production from hydrate reservoir at the 1st offshore test site in the eastern Nankai Trough," Journal of Natural Gas Science and Engineering, vol. 30, pp. 64-76, 2016.

[18] J. Rutqvist and G. J. Moridis, "Coupled hydrologic, thermal and geomechanical analysis of well bore stability in hydrate-bearing sediments," in Proceedings of Offshore Technology Conference, 2008.

[19] S. Uchida, K. Soga, A. Klar, and K. Yamamoto, "Geomechanical study of the Mallik gas hydrate production field trials," Bulletin of the Geological Survey Canada, vol. 601, pp. 191-204, 2012.

[20] M. Jiang, H. Chen, M. Tapias, M. Arroyo, and R. Fang, "Study of mechanical behavior and strain localization of methane hydrate bearing sediments with different saturations by a new DEM model," Computers \& Geosciences, vol. 57, pp. 122-138, 2014.

[21] S. Uchida, A. Klar, and K. Yamamoto, "Sand production model in gas hydrate-bearing sediments," International Journal of Rock Mechanics and Mining Sciences, vol. 86, pp. 303-316, 2016.

[22] T. Fujii, K. Suzuki, T. Takayama et al., "Geological setting and characterization of a methane hydrate reservoir distributed at the first offshore production test site on the Daini-Atsumi Knoll in the eastern Nankai Trough, Japan," Marine and Petroleum Geology, vol. 66, pp. 310-322, 2015.

[23] K. Yamamoto, T. Kanno, X.-X. Wang et al., “Thermal responses of a gas hydrate-bearing sediment to a depressurization operation," RSC Advances, vol. 7, no. 10, pp. 5554-5577, 2017.

[24] K. Suzuki and H. Narita, "Estimation of Permeability of methane hydrate-bearing strata of Nankai Trough, in comparison to core measurement vs. CMR analysis," Journal of the Japanese Association for Petroleum Technology, vol. 75, pp. 98$105,2010$.

[25] X. Wang, T. S. Collett, M. W. Lee, S. Yang, Y. Guo, and S. Wu, "Geological controls on the occurrence of gas hydrate from core, downhole log, and seismic data in the Shenhu area, South China Sea," Marine Geology, vol. 357, pp. 272-292, 2014.

[26] L. Huang, Z. Su, and N.-Y. Wu, "Evaluation on the gas production potential of different lithological hydrate accumulations in marine environment," Energy, vol. 91, pp. 782-798, 2015.

[27] Y. Komatsu, K. Suzuki, and T. Fujii, "Sedimentary facies and paleoenvironments of a gas-hydrate-bearing sediment core in the eastern Nankai Trough, Japan," Marine and Petroleum Geology, vol. 66, pp. 358-367, 2015.

[28] T. Fujii, S. Noguchi, T. Takayama, K. Suzuki, K. Yamamoto, and T. Saeki, "Site selection and formation evaluation at the 1st offshore methane hydrate production test site in the Eastern Nankai Trough, Japan," in Proceedings of the 75th EAGE Conference and Exhibition Incorporating SPE EUROPEC 2013, gbr, June 2013.

[29] K. Yamamoto, Y. Terao, T. Fujii et al., "Operational overview of the first offshore production test of methane hydrates in the Eastern Nankai Trough," in Proceedings of the Offshore 
Technology Conference 2014, OTC 2014, pp. 1802-1812, usa, May 2014.

[30] S. Yang, M. Zhang, J. Liang et al., "Preliminary results of China's third gas hydrate drilling expedition: a critical step from discovery to development in the South China Sea," Fire in the Ice, vol. 15, pp. 1-5, 2015.

[31] G. Archie, "The Electrical Resistivity Log as an Aid in Determining Some Reservoir Characteristics," Transactions of the AIME, vol. 146, no. 01, pp. 54-62, 2013.

[32] Y. Terao, M. Duncan, B. Hay, and L. Dang, "Deepwater methane hydrate gravel packing completion results and challenges," in Proceedings of the Offshore Technology Conference 2014, OTC 2014, pp. 2682-2695, usa, May 2014.

[33] G. J. Moridis and M. T. Reagan, Strategies for gas production from oceanic class 3 hydrate accumulations, Lawrence Berkeley National Laboratory, 2007.

[34] G. J. Moridis and M. T. Reagan, "Estimating the upper limit of gas production from Class 2 hydrate accumulations in the permafrost: 1 . Concepts, system description, and the production base case," Journal of Petroleum Science and Engineering, vol. 76, no. 3-4, pp. 194-204, 2011.

[35] G. J. Moridis, Y. Seol, and T. J. Kneafsey, Studies of reaction kinetics of methane hydrate dissocation in porous media, Lawrence Berkeley National Laboratory, 2005.

[36] M. T. van Genuchten, "A closed-form equation for predicting the hydraulic conductivity of unsaturated soils," Soil Science Society of America Journal, vol. 44, no. 5, pp. 892-898, 1980.

[37] M. Kurihara, K. Funatsu, H. Ouchi et al., "Analysis of 2007/2008 JOGMEC/NRCan/Aurora Mallik gas hydrate production test through numerical simulation," in Proceedings of the 7th International Conference on Gas Hydrates, Edinburgh, Scotland, United Kingdom, 2011.

[38] M. Uddin, F. Wright, S. Dallimore, and D. Coombe, "Gas hydrate dissociations in Mallik hydrate bearing zones A, B, and $C$ by depressurization: Effect of salinity and hydration number in hydrate dissociation," Journal of Natural Gas Science and Engineering, vol. 21, pp. 40-63, 2014.

[39] T. Kanno, M. Takekoshi, X. Wang et al., "In-situ temperature measurement of gas hydrate dissociation during the worldfirst offshore production test," in Proceedings of the Offshore Technology Conference 2014, OTC 2014, pp. 1709-1713, usa, May 2014. 

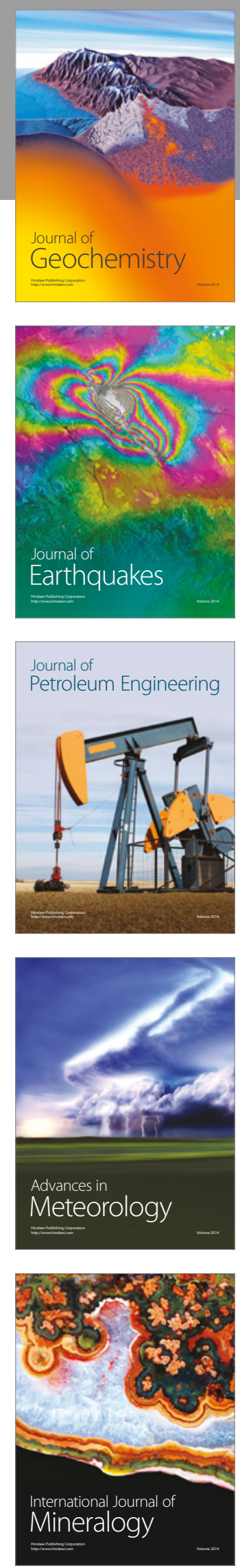
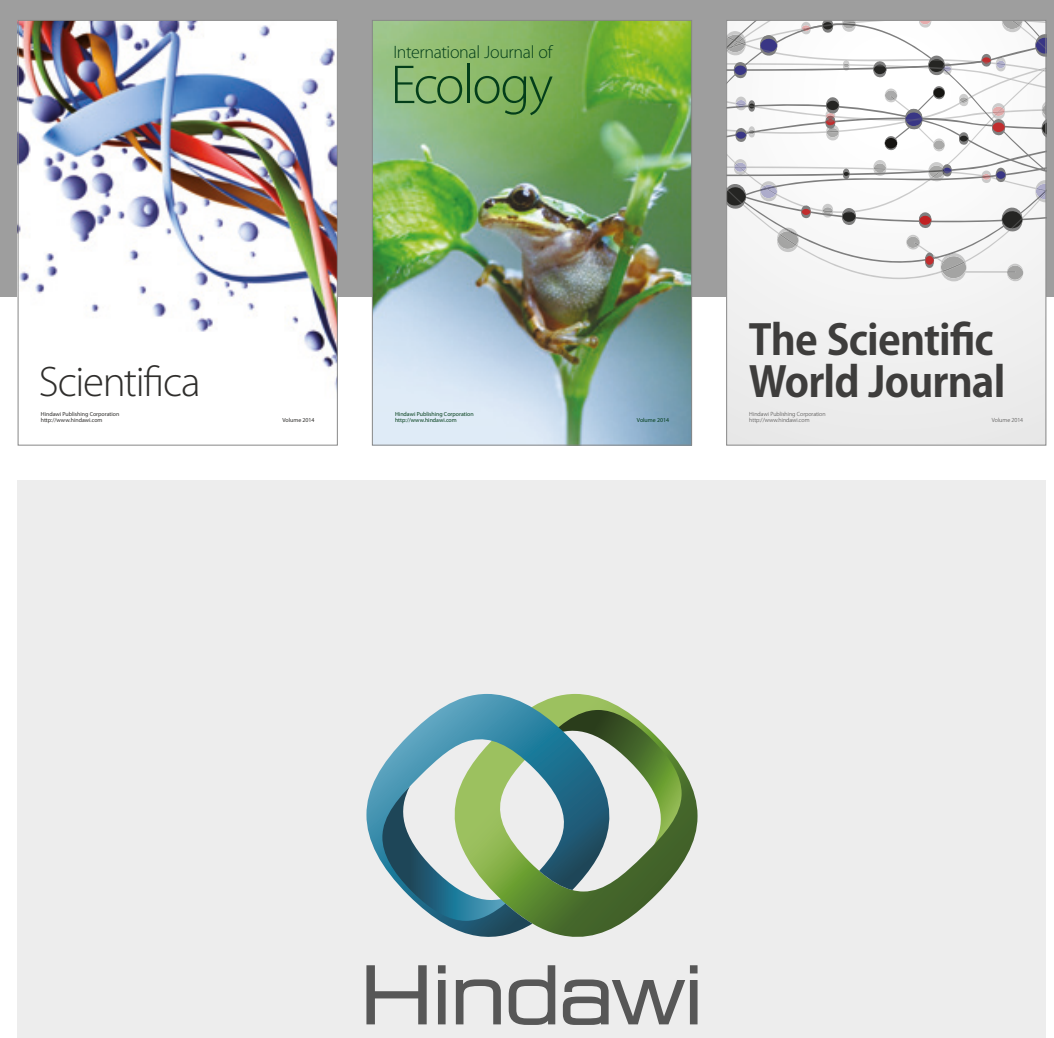

Submit your manuscripts at

https://www.hindawi.com
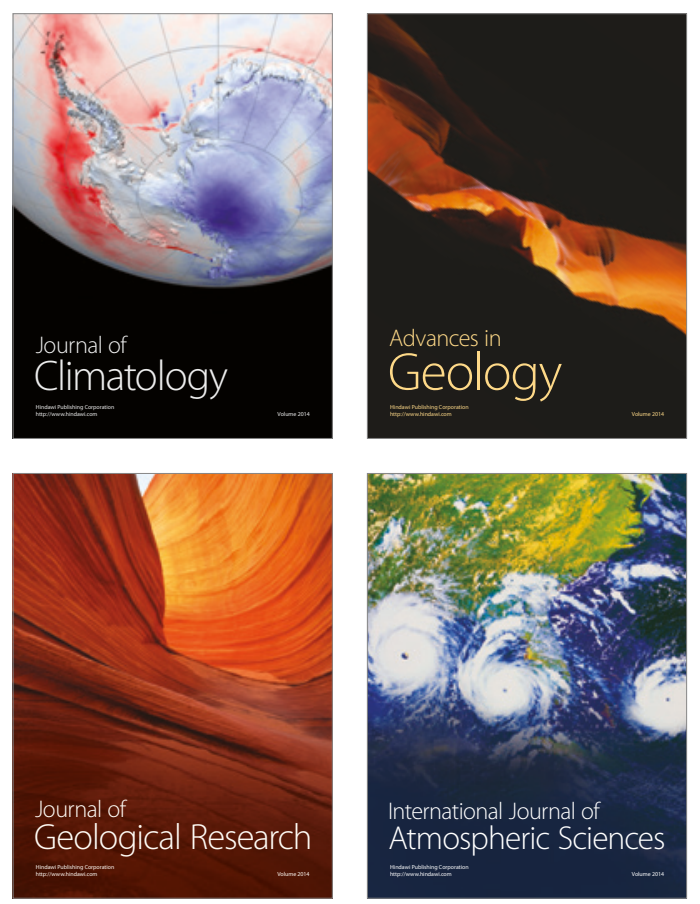

The Scientific

World Journal
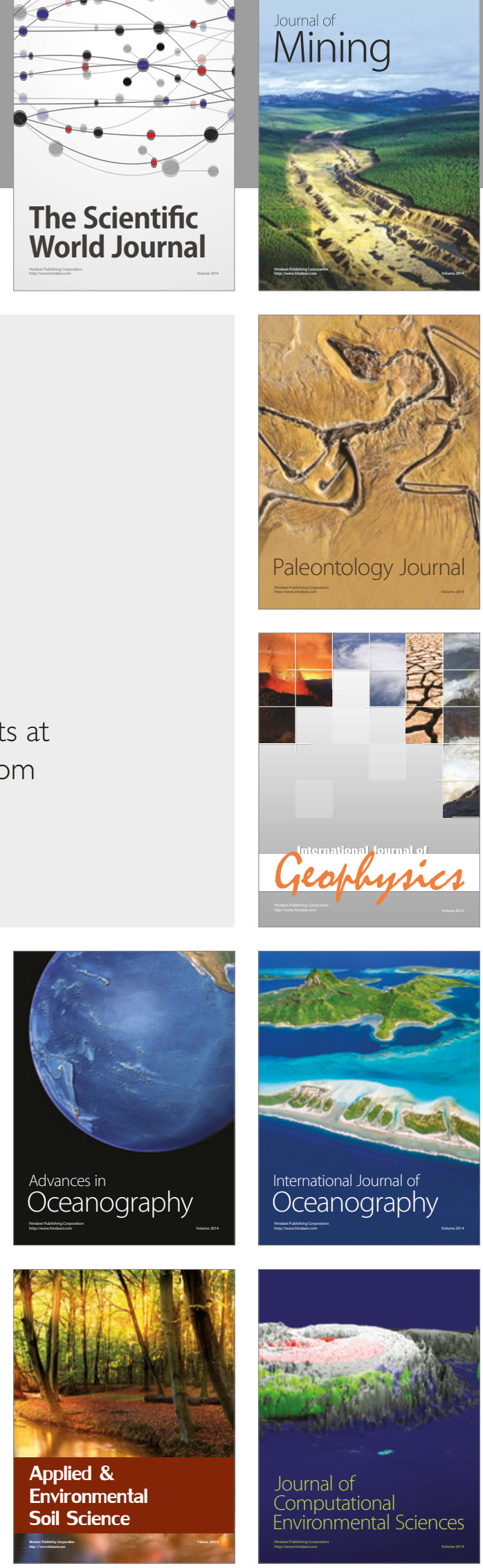